\title{
PROCESSOS DISCURSIVOS DE ORALIDADE E DE ESCRITA NO ENSINO DE LÍNGUA PORTUGUESA
}

\author{
Maria Valíria Aderson de Mello Vargas
}

\begin{abstract}
Resumo: Busca-se discutir, neste trabalho, o papel que os procedimentos discursivos de oralidade e de escrita podem desempenhar nas atividades de ensino e aprendizado da língua portuguesa. Para tanto, expõem-se as relações que se estabelecem entre as duas modalidades em questão (a oralidade e a escrita) $e$ apontam-se algumas estratégias para levar o aluno a compreender os diferentes usos da língua como legítimas manifestações de linguagem, desde que adequados às intenções, aos interlocutores envolvidos e aos contextos em que são enunciados.
\end{abstract}

Palavras-chave: oralidade e escrita; discurso e texto; ensino de Lingua Portuguesa; língua falada e língua escrita.

\section{Introdução}

A reflexão que se apresenta neste trabalho insere-se nos propósitos de uma linha de pesquisa voltada para a discussão das teorias e práticas discursivas, das concepções de língua, linguagem, discurso e texto, das relações entre oralidade e escrita, e das possibilidades de aplicação desses estudos às atividades de ensino da língua portuguesa. Busca-se, desse modo, um conhecimento mais abrangente e efetivo do objeto de ensino que é a língua, e, mais amplamente, a linguagem, e, sobretudo, a sua prática, reveladora das condições sócio-históricas, que envolvem os sujeitos que a utilizam.

Considerando-se que a língua, embora apresente certa estabilidade formal, é uma atividade contextualmente situada, cognitivamente determinada e historicamente constituída (MARCUSCHI, 1998, p.16), propõe-se discutir o modo como devem ser tratadas as duas modalidades de língua (falada e escrita) no ensino do português, sem atribuir maior importância a uma ou a outra, reconhecendo seu valor social e não estabelecendo entre elas relações dicotômicas. Rebate-se, portanto, a tendência tradicional de atribuir-se maior valor ao texto escrito e considera-se que se deve exercitar com o aluno, tanto nas atividades de expressão oral quanto nas de escrita, o domínio da modalidade padrão, não como uma forma substitutiva, mas como uma nova forma a seu dispor para certos propósitos discursivos.

\footnotetext{
* Professora aposentada da FFLCH-USP e Docente do Quadro Permanente do Programa de Mestrado em Lingüística da Universidade Cruzeiro do Sul (UNICSUL).
} 
Defende-se, ainda, que a língua falada deve ser analisada por métodos próprios - por exemplo, considerando-se os processos discursivos de construção, de reconstrução e de descontinuação que constituem essa modalidade, de acordo com a hipótese formulada por Castilho (1994, p.47). Tais métodos devem compreender as mais variadas formas de interação verbal, ou seja, devem considerar a fala em suas condições de uso, de interlocução. Assim, pode-se oferecer aos alunos a oportunidade de perceberem a riqueza que envolve o uso efetivo da língua como fator de identidade, do qual não se pode abrir mão. Isso não significa transformar a fala num conteúdo autônomo no ensino de língua, mas considerá-la em sua relação e interação com a escrita.

Nesse sentido, torna-se também necessário definir-se o tipo de escrita que se pretende ensinar, bem como os critérios a serem adotados na seleção de textos mais adequados a esse ensino, uma vez que a escrita varia, que existem escritas formais e informais e que há uma série de gêneros textuais escritos.

\section{Oralidade e escrita}

Sabe-se que toda a atividade lingüística sempre se realiza, na escola ou fora dela, como discurso ou texto, numa determinada situação de comunicação. É recorrente, portanto, a idéia de que o texto deve ser compreendido como um processo de comunicação e interação.

No texto oral, os interlocutores estão mais atentos às particularidades dessa situação concreta de comunicação. Conforme argumenta Brait (1993, p.195), a dinâmica da interação decorre da percepção, por parte dos interlocutores, dos aspectos que constituem o diálogo: quem é o outro a que o projeto de fala se dirige; quais são as intenções do falante com sua fala, com a maneira de organizar as sequiências dessa fala; que estratégias utiliza para se fazer compreender, compreender o outro e encaminhar a conversa de forma mais adequada; como levar o outro a cooperar no processo. Isso implica a mobilização, além do instrumental lingüístico oferecido pela língua enquanto sistema, de normas e estratégias de uso que se combinam com outras regras culturais, sociais e situacionais, conhecidas e reconhecidas pelos participantes do evento conversacional.

É fundamental, portanto, não perder de vista que o processo de aquisição e desenvolvimento das habilidades de leitura e de produção de textos, levado a efeito na escola, insere-se no contexto mais amplo da relação que se estabelece entre a oralidade e a escrita, entre o discurso ou texto oral e o discurso ou texto escrito.

Por essa razão, justifica-se a idéia de que o texto não deve ser analisado como se fosse um produto acabado, passível de ser decomposto em partes estanques e tomado como simples objeto de exercícios gramaticais ou de estilo, por exemplo. É fundamental realçar, nas atividades didáticas, o processo de construção de sentido do texto, decorrente da ação cooperativa dos envolvidos na interação e da cumplicidade entre eles, já que participam de uma mesma realidade histórica e social e devem compartilhar determinadas visões de mundo. 
Os alunos devem compreender que o significado do texto se constrói nessa interação cooperativa dos interlocutores e que essa construção de sentidos significa voltar a atenção para uma tarefa comum e sinalizá-la. Essa sinalização, conforme esclarece Marcuschi (1998, p.34), tem marcas que se dão em atividades rituais como os olhares, os movimentos do corpo, os sinais de atenção, os marcadores conversacionais produzidos com uma certa carga entoacional e assim por diante. A atividade interacional resulta, assim, de certos procedimentos adotados durante a conversação que decorrem de pressupostos cognitivos e culturais.

Rodrigues (1993, p. 23), apoiando-se em Chafe (1985), lembra o trabalho cooperativo entre interlocutores que fundamenta o processo conversacional. Esse envolvimento "a duas vozes", como prega a autora, resulta da utilização de vários recursos ou processos: monitoração, pelo falante, do canal de comunicação; tentativa de formar imagens que causem no ouvinte a sensação do imediato, da proximidade e da riqueza de experiência, ou seja, o senso do "concreto". Decorre disso o caráter fragmentário do texto oral, que se constrói por meio da alternância de turnos, da utilização do discurso direto, da inclusão de pormenores, do uso de partículas enfáticas. A mensagem fragmentada do texto falado está, desse modo, associada às características do fluxo da fala, à sua maior velocidade, e contrapõe-se à menor velocidade da escrita, ao grau maior de integração dessa modalidade, que está associada a três etapas básicas: planejamento, execução e revisão.

Insistindo-se nessas idéias, cabe lembrar que, na interação oral, dá-se o envolvimento maior do falante com a situação comunicativa, com seu interlocutor, uma vez que eles estão situados num mesmo contexto e partilham conhecimentos comuns, o que permite truncamentos e omissões. Já o texto escrito é marcado por um alto grau de integração entre autor e leitor, embora estes não ocupem o mesmo espaço e o mesmo tempo no momento da elaboração e da decodificação da mensagem escrita. Por tratar-se de interação que ocorre a distância, como bem lembram Fávero, Andrade e Aquino (1999, p.78), no texto escrito, há um real envolvimento do autor com o texto, com um leitor imaginado e com o tópico em questão.

Evidencia-se, assim, que a situação de comunicação da língua escrita é diferente da situação de interação da língua oral, embora o sistema lingüístico seja o mesmo nas duas modalidades. Os interlocutores do texto escrito não interagem face a face; o autor não conhece as reações que as palavras provocam, não conta com os recursos entoacionais, pensa para escrever e tem a oportunidade de refazer o texto, corrigi-lo, reelaborá-lo, o que não ocorre na situação de fala. Sobre a produção do texto escrito, como constata Preti (1993, p.219), pesa intensamente uma cultura lingüística, o nível de escolaridade, pesam as leituras, os conhecimentos gramaticais, a possibilidade de consultar o dicionário. Para Preti, esses são fatores de controle dos textos que redigimos e a tendência, pois, é atendermos com mais atenção às normas da linguagem culta escrita, ainda que o coloquial, o falado, possa fazer parte de nosso estilo.

Tudo isso leva a concluir que a interpretação do texto deve sempre pressupor diálogo, interação. Ademais, a leitura ativa e crítica de textos dos mais variados gêneros que circulam socialmente se apresenta como um procedimento necessário à prática de produção textual. Esta será mais eficaz se for considerada como um processo decorrente da leitura ativa e crítica de uma dada realidade, uma construção de conhecimento que 
intencionalmente vai se refletir no outro. Trata-se, portanto, de uma maneira de organizar lingüisticamente os variados conhecimentos e experiências, levando-se, necessariamente, em conta os possíveis leitores.

\section{Processos discursivos de oralidade e escrita na sala de aula}

Considerando-se que a sala de aula deve ser um espaço de debate permanente, um local onde os alunos escutam a voz do outro e, ao mesmo tempo, ajustam seu discurso ao do outro, o trabalho com a oralidade deve voltar-se, sobretudo, para a busca da clareza na exposição das idéias e da consistência argumentativa na defesa de pontos de vista. Nesse espaço, o aluno deverá encontrar a chance de desenvolver seus conhecimentos discursivos e lingüísticos, aprendendo a expressar-se adequadamente nas diferentes situações de interação social e sensibilizando-se para a adequação da variedade lingüística (variação dialetal, redundâncias, repetições, marcadores conversacionais) ao contexto de comunicação. A escola, enfim, deverá proporcionar ao aluno a oportunidade de conviver com a grande variedade de usos da língua e de compreender que ela não é homogênea, monolítica, mas apresenta diferentes níveis nas duas modalidades - escrita e falada - do mais coloquial ao mais formal.

Desse modo, o próprio aluno poderá reconhecer que a questão não é falar "certo" ou "errado", e sim saber o que utilizar, de acordo com as características do contexto de comunicação, ou seja, saber adequar o registro às diferentes situações comunicativas, conforme pregam os Parâmetros Curriculares Nacionais (1998, p.59). Isso significa que é papel da escola oferecer ao aluno a chance de aprender a coordenar satisfatoriamente o que falar e como fazê-lo, considerando a quem e por que se diz determinada coisa.

Atividades que levem o aluno a transformar textos falados em textos escritos ou a observar a organização de textos das duas modalidades são estratégias eficientes para que ele compreenda o funcionamento da linguagem e, assim, desenvolva adequadamente os processos discursivos de oralidade e escrita, necessários para continuar aprendendo e para participar das práticas sociais que envolvem esses conhecimentos.

Já se mostrou ineficaz a tendência de levar o aluno a observar a fala a partir da escrita, sem considerar o grau de autonomia que deve existir entre as duas modalidades. $\mathrm{O}$ aluno deve ser capaz de compreender que o texto escrito não é uma transcrição da fala e que fala e escrita são diferentes instrumentos de ação social. Deve estar ciente de que, por essa razão, não se escreve como se fala, nem são as mesmas as circunstâncias em que se escreve ou se fala.

Por essas razões, os textos a serem utilizados, sobretudo nas séries dos ciclos iniciais do ensino fundamental, devem ser sempre contextualizados em uma atividade oral, que pode consistir na leitura do professor, no diálogo, na conversa, nas pequenas dramatizações, nos jogos, em que cada texto vai ganhando sua significação. Por meio dessas atividades orais e dialogadas, promove-se a troca de experiências entre os alunos e é nesse trabalho conjunto e partilhado que se constrói o conhecimento e se facilita a 
elaboração das hipóteses fundamentais com que as crianças vão operar no desenvolvimento da escrita.

Assim, a linguagem escrita não pode ser definida como um conjunto de propriedades formais, invariantes e distintas da língua falada. $\mathrm{Na}$ verdade, as duas modalidades correlacionam-se, já que selecionam os seus recursos expressivos do mesmo sistema gramatical e podem expressar as mesmas intenções.

Não há dúvida de que o texto escrito possui um valor social específico. Há, nesse caso, cobranças muito mais fortes em relação à norma culta padrão, por exemplo. Decorre disso a necessidade de proporcionar ao aluno as condições para que aprenda a optar entre as diferentes variantes, de acordo com as intenções e com os possíveis interlocutores, e a manejar os diferentes estilos e modalidades textuais.

As propostas de produção escrita que a escola tradicionalmente apresenta consistem em certos comandos a que os alunos devem obedecer. Não há, em geral, a determinação do interlocutor; não se define com precisão o tipo de texto a ser produzido, nem a forma de organização e de apresentação das idéias; tampouco se determina o tipo de linguagem a ser empregada. O professor, nesse caso, figura como o leitor absoluto, real, dos textos, o que influi sobremaneira na produção do aluno. $O$ texto produzido nessas condições certamente se diferencia de um texto decorrente de uma proposta que pretenda levar o aluno a definir um interlocutor a quem se dirigir, bem como a planejar o texto, selecionar as informações, experiências e atitudes mais adequadas a seus propósitos e tema e a descobrir alternativas de composição textual e de modos de expressão mais adequados a seu projeto.

As questões do texto se estendem, assim, para muito além das questões mais específicas da gramática, das modalidades de linguagem, do estilo, dos recursos expressivos, para incorporar essas dimensões discursivas que incluem os interlocutores, as relações que se estabelecem entre eles, os conhecimentos que juntos constroem, as intenções e propósitos específicos do texto e as circunstâncias sociais em que se manifestam.

Não se propõe, aqui, que se abandone, na sala de aula, a descrição gramatical sistemática, ou seja, que não se apresentem ao aluno questões sobre classificação das palavras e orações, identificações de relações e funções gramaticais, questões sobre regência, concordância, ordem das palavras, emprego de certas expressões lingüísticas. $O$ que se quer dizer é que essa tarefa fica bem mais simples se os alunos estiverem habituados a operar sobre a própria linguagem. Pode-se estimular um trabalho de construção e transformação de textos, mediante diferentes operações gramaticais, nas séries iniciais do ensino fundamental, e deixar a descrição gramatical mais sistemática para as séries mais avançadas. Isso não significa que não se possa antecipar a abordagem de certos fatos gramaticais nas séries iniciais, quando a própria discussão desses fatos acaba exigindo do professor e dos alunos o uso de algumas palavras técnicas e algumas distinções de categorias, relações ou funções gramaticais. $\mathrm{O}$ foco, entretanto, deve dirigir-se aos aspectos mais importantes do aprendizado gramatical, que consiste no domínio efetivo e no uso adequado das várias modalidades de construção e transformação das expressões lingüísticas na atividade de produção do texto, oral ou escrito. 


\section{Considerações finais}

Com estas reflexões, busca-se, enfim, ressaltar que, no processo de ensino e aprendizagem da língua materna, o professor deve considerar as diferenças que marcam as duas modalidades discursivas ou textuais e verificar as possibilidades de interpretação das estratégias de oralidade e de escrita utilizadas nos diferentes tipos de textos, buscando descobrir, juntamente com os alunos, como ocorrem e por que ocorrem. Desse modo, as atividades de produção oral e escrita certamente serão mais motivadoras e eficientes para levar o aluno a adquirir a necessária autonomia e o controle do que fala ou escreve. $\mathrm{O}$ professor, diante disso, pode também estabelecer critérios mais apropriados para a avaliação da produção do aluno.

O professor, aliás, precisa exercer constantemente o papel de mediador eficaz no processo de desenvolvimento das habilidades de leitura e de produção de textos; a ele cabe, ainda, observar com muito cuidado as características dos textos orais produzidos pelos alunos e avaliar o grau de interação das atividades de oralidade e de escrita. Também é papel do professor verificar o modo como o aluno incorpora, passo a passo, à sua produção os procedimentos ou os recursos expressivos próprios da modalidade escrita, tendo em vista o contato mais freqüente com a leitura de textos dos mais variados gêneros que circulam socialmente.

É preciso lembrar que todas as atividades de linguagem, de produção e interpretação de textos orais e escritos devem ocorrer em um contexto significativo, que se estabelece inicialmente como uma extensão do contexto comunicativo familiar e da comunidade, mas que logo se amplia para novas situações sociais e interpessoais diferenciadas, com novos propósitos e novas exigências formais.

Com isso, a escola figurará, de fato, como um ambiente de rica interação, em que os alunos vivem múltiplas experiências e situações reais de linguagem e de construção partilhada de conhecimentos. A sistematização e a representação desses conhecimentos deverão decorrer de uma intensa exposição prévia aos dados oferecidos nas diferentes situações de uso da língua, bem como das operações sobre a própria linguagem. Assim, as atividades didáticas que envolvem a conversação, as dramatizações, os relatos e histórias, a transformação e reconstrução de textos e o acesso aos mais variados gêneros textuais tornam-se eficientes procedimentos para o efetivo aprendizado da língua materna.

O sucesso desse trabalho didático, convém ainda lembrar, está diretamente relacionado à atitude do professor, que deve ter consciência de seus próprios limites e que, naturalmente, deve sanar suas dificuldades, buscando novas informações que fundamentem e reformulem sua prática docente.

\section{Referências Bibliográficas}

BRAIT, B. O processo interacional. In: Análise de Textos Orais (Org. Dino Preti). São Paulo: FFLCH/USP, 1993, p. 189-214. 
Elocução formal: $\mathrm{O}$ dinamismo da oralidade e as formalidades da escrita. In: Estudos de Língua Falada. Variações e confrontos. (Org. Dino Preti) São Paulo: Humanitas/FFLCH- USP, 1998, p. 87-108.

BRASIL. Secretaria de Educação Fundamental. Parâmetros Curriculares Nacionais de: Língua Portuguesa. Ensino Fundamental 3º $4^{\circ}$ ciclos. Brasília: MEC/SEF, 1998.

CASTILHO, A. T. de. Problemas de descrição da língua falada. D.E.L.T.A., São Paulo, v.10, nº 1, p. 47-71.

Problemas de análise gramatical. In: Subsídios à Proposta Curricular de Língua Portuguesa para o $1^{o}$ e $2^{o}$ graus. Coletânea de Textos. Vol. II. São Paulo: SE/CENP, 1988.

FÁVERO, L.; ANDRADE, M.L.C.V.O; AQUINO, Z.G.O. Oralidade e escrita. Perspectivas para o ensino de língua materna. São Paulo: Cortez Editora, 1999.

MARCUSCHI, L. A. Atividades de compreensão na interação verbal. In: Estudos de língua falada: variações e confrontos (Org. Dino Preti). São Paulo: Humanitas/FFLCH/USP, 1998, p. 15-45.

PRETI, D. A língua falada e o diálogo literário. In: Análise de Textos Orais (Org. Dino Preti). São Paulo: FFLCH -USP, 1993, p. 215-228.

RODRIGUES, A.C.S. Língua falada e língua escrita. In: Análise de Textos Orais (Org. Dino Preti). São Paulo: FFLCH/USP, 1993, p. 13-32.

\begin{abstract}
We aim to discuss, in this article, the role that the discursive procedures of orality and writing can play in the activities of teaching and learning Portuguese. Therefore, it's going to be shown the relations which are established between the two modalities in question (orality and writing) and pointed some strategies to help the student understand the different usages of language as legitimate language manifestations, as long as adequate to the intentions, to the interlocutors involved and to the contexts in which they are enounced.
\end{abstract}

Keywords: orality and writing; discourse and text; teaching of Portuguese; oral and written language. 